\title{
Synthesis of Poly( $N$-isopropylacrylamide) Gel and Core-Shell Type Gel with Thermo-Sensitive Shell Layer by Amidation of Poly(acrylic acid) Gel
}

\author{
Takashi IIzAwA, ${ }^{\dagger}$ Naoki MatsunO, Masashi TAKeuchi, \\ and Fumihiko MATSUDA \\ Department of Chemical Engineering, Graduate School of Engineering, Hiroshima \\ University, Kagamiyama, Higashi-Hiroshima 739-8527, Japan
}

(Received October 9, 2001; Accepted December 4, 2001)

\begin{abstract}
To synthesize a novel gel capsule containing a thermo-sensitive shell and hydrophilic core portions, we investigated the amidation of poly(acrylic acid) (AA) gel-1,8-diazabicyclo[5,4,0]undec-7-ene salt (DAA) with isopropylamine (IPA). The reaction of DAA with IPA proceeded almost quantitatively in NMP in the presence of triphenylphosphine (TPP). However, the amidation took place in competition with the esterification to give a copolymer of $\mathrm{N}$-isopropylacrylamide with phenyl acrylate. The selectivity of amidation increased with increasing the IPA concentration although the observed decreasing rate of unswollen part was independent of the concentration. When the reaction was carried out at $1.0 \mathrm{~mol} \mathrm{~L}^{-1}$ of the IPA concentration in NMP, the amidation from the outside took place almost selectively to give poly( $N$-isopropylacrylamide) gel through a DAA-NIPA type gel capsule consisting of a hydrophilic unreacted core part and amidated shell layer. The swelling of the gel capsule and release of Methyl Orange from the gel capsule were studied. Above the lower critical solution temperature (LCST) of poly( $N$-isopropylacrylamide) gel, the gel capsule swelled as well as DAA, and the shell layer did not work as a permeability barrier of water. However, an AA-NIPA type gel capsule containing a AA core part and thermo-sensitive shell layer, which was prepared from the neutralization of DAA-NIPA type gel capsule, showed on-off chemical release in response to stepwise temperature changes cross the LCST.

KEY WORDS Core-Shell Type Gel / 1,8-Diazabicyclo-[5,4,0]-7-undecene / Amidation / Poly(acrylic acid) Gel / Poly ( $N$-isopropylacrylamide) Gel / Thermo-Sensitive /
\end{abstract}

Polymers with pendant carboxylic acids such as poly(acrylic acid) (AA) and poly(methacrylic acid) are interesting starting polymers for synthesis of functional polymers because the reactions of pendant carboxylic acid such as neutralization, esterification, and amidation are useful for the modifications. However, quantitative esterification and amidation of these polymers are very difficult since the property of resulting polymers changes dramatically from hydrophilicity to hydrophobicity.

Nishikubo and Iizawa et al. ${ }^{1}$ have studied the esterification of pendant carboxylic acids in polymers with alkyl halides using 1,8-diazabicyclo-[5,4,0]-7undecene (DBU) as an acid acceptor. The quantitative esterification is achieved under mild conditions using DBU as an acid acceptor in an aprotic polar solvent. When DBU salt (DAA) of AA gel was used, the esterification with alkyl halide proceeded from the outside to give a core-shell type gel (gel capsule) consisting of an esterified shell layer and hydrophilic unreacted core part. ${ }^{2}$ This method is suitable for synthesis of core-shell type gels of $\mathrm{mm}$ size or over. Other reactions such as a selective thermal acid-catalyzed deesterification of internal poly $(t$-butyl

${ }^{\dagger}$ To whom all correspondence should be addressed. methacrylate) gel in a solvent, ${ }^{3}$ which show high reactivity and selectivity, may be applicable to synthesis of gel capsules. Also, the reactions could be expected to introduce functionalities except for hydrophobicity into the shell layer. We paid attention to thermo-sensitive $\operatorname{poly}(N$-isopropylacrylamide $)$ (NIPA) which has lower critical solution temperature (LCST) in the vicinity of $32^{\circ} \mathrm{C} .{ }^{4}$ This polymer has not been prepared except radical polymerization of $N$ isopropylacrylamide. Recently, Akashi et al. ${ }^{5}$ have reported that its isomer, poly( $N$-vinylisobutyramide) was prepared by the condensation of poly(vinylamine) hydrochloride with isobutyric acid using 1-ethyl-3[3-(dimethylamino)propyl]carbodiimide hydrochloride and triethylamine as activating agents. However, the degree of acylation was not satisfactorily high. The synthesis of poly $(N$-isopropylacrylamide) from the condensation of AA with isopropylamine (IPA) requires for activating agents with high reactivity and selectivity because the LCST of $\operatorname{poly}(N-$ isopropylacrylamide) is very sensitive to small amounts of impurities such as unreacted acrylic acid units and by-products. ${ }^{6}$ These agents have been investigated widely in direct polycondensation. ${ }^{7}$ Higash $^{7 \mathrm{a}}$ studied synthesis of polyamide with high molecular weight by 


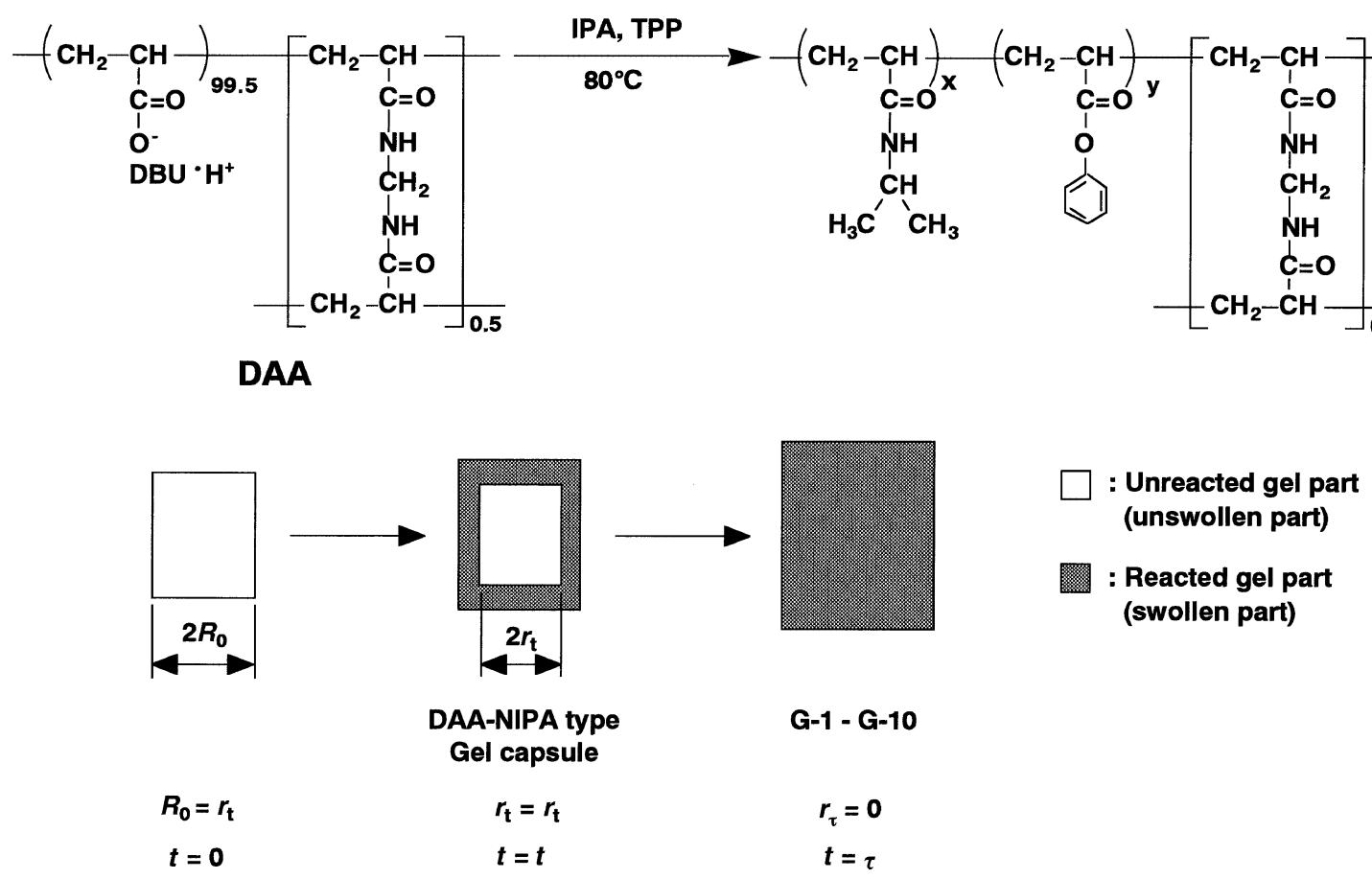

Scheme 1. Reaction of DAA with IPA using TPP.

the direct polycondensation of dicarboxylic acid with aromatic diamine using triphenylphosphite (TPP) and pyridine system. Yamazaki and Higashi ${ }^{8}$ also studied peptide synthesis using the TPP and pyridine system. However, the reaction of carboxylic acid with aliphatic amine shows lower selectivity than that with aromatic amine using this system, although the former reaction has higher reactivity than the latter.

The previous communication ${ }^{9}$ reported the successful synthesis of poly $(N$-isopropylacrylamide $)$ gel from amidation of DAA with IPA in the presence of TPP as an activating agent. This study reports that the amidation of DAA with IPA is investigated in detailed. Selective amidation from the outside would afford $\operatorname{poly}(N$ isopropylacrylamide) gel through a novel gel capsule consisting of a hydrophilic unreacted core and thermosensitive shell (Scheme 1). The shell layer would be expected to show dramatic permeability changes for many chemicals in response to temperature changes cross the LCST. We also discuss the preparation and the characterization of the gel capsule prepared from this reaction.

\section{EXPERIMENTAL}

\section{Materials}

Monomers and solvents were distilled prior to use. Commercial $N, N^{\prime}$-methylenebisacrylamide, DBU, IPA, TPP, diphenylphosphite (DPP), and Methyl Orange were used without further purification. Cylindrical DAA (length and diameter $\left(2 \mathrm{R}_{0}\right.$ : about $5.0 \mathrm{~mm}$ ) was prepared via two-steps; the copoly- merization of acrylic acid with $0.5 \mathrm{~mol} \%$ of $N, N^{\prime}$ methylenebisacrylamide in Teflon tubes (internal diameter; $6.0 \mathrm{~mm}$ ) and neutralization of the resulting gel with excess DBU in methanol according to the previous papers. ${ }^{3 b}$ Poly(phenyl acrylate) and poly $(N$-isopropylacrylamide) were prepared by radical polymerization of the corresponding monomer in the presence of 2,2'-azobis(isobutyronitrile) in $N, N$ dimethylformamide (DMF) at $60^{\circ} \mathrm{C}$ for $24 \mathrm{~h}$.

\section{Apparatus}

IR spectra were obtained on a JASCO model IR-700 spectrophotometer. UV spectra were measured on a Shimadzu model UV 2100S spectrophotometer.

\section{Amidation of DAA}

A typical amidation was as follows. A mixture solution of TPP $\left(1.0 \mathrm{~mol} \mathrm{~L}^{-1}\right)$ and IPA $\left(1.0 \mathrm{~mol} \mathrm{~L}^{-1}\right)$ in $\mathrm{N}$-methyl-2-pyrrolidone (NMP) $(50 \mathrm{~mL})$ was charged into a $50 \mathrm{~mL}$ cylindrical cell in a water bath at $80^{\circ} \mathrm{C}$. A cylindrical DAA was dipped in the solution. The gel began swelling and divided into a swollen shell and unswollen core. Radius $\left(r_{\mathrm{t}}\right)$ of the core after $t=t \mathrm{~min}$ were periodically observed by a digital video camera (Sonny, DCR-VX1000). After the disappearance of the core, the resulting gel was washed away unreacted substances and by-products with methanol by a Soxhlet extractor. It was dried slowly, and finally dried in vacuo at $80^{\circ} \mathrm{C}$ until constant weight. The gel was dipped in TEA solution in THF $\left(10 \mathrm{mmol} \mathrm{L}^{-1}, 25 \mathrm{~mL}\right)$ at room temperature for $24 \mathrm{~h}$. Although free carboxylic acid in 
the gel was measured by neutralization titration of the filtrate with $10 \mathrm{mmol} \mathrm{L}^{-1}$ aqueous $\mathrm{HCl}$ solution, it was not detected. The degree of amidation was $96.2 \%$, calculated from $A_{\text {ester }} / A_{\text {amide }}$, where $A_{\text {ester }}$ and $A_{\text {amide }}$ are absorptions at 1755 and $1650 \mathrm{~cm}^{-1}$, respectively.

\section{Synthesis of DAA-NIPA Type Gel Capsules}

A typical synthesis of DAA-NIPA type gel capsules was as follows. $200 \mathrm{~mL}$ of the mixed solution of TPP $\left(1.0 \mathrm{~mol} \mathrm{~L}^{-1}\right)$ and IPA $\left(1.0 \mathrm{~mol} \mathrm{~L}^{-1}\right)$ in NMP was charged into $300 \mathrm{~mL}$ of Erlenmeyer flask in a water bath at $80^{\circ} \mathrm{C}$. Dozens of DAA samples $\left(2 R_{0}=5.0 \mathrm{~mm}\right)$ were soaked in this solution, and were kept till the thickness of shell layer $\left(1-r_{\mathrm{t}} / R_{0}\right)$ became 0.10 for 55 min. The gels were taken out from the reaction mixture, and were placed into a large quantity of methanol to stop the reaction. After the reaction, they were sufficiently washed with methanol with a Soxhlet extractor. They were dried carefully and slowly, and finally dried in vacuo at $60^{\circ} \mathrm{C}$ until constant weight.

\section{Synthesis of AA-NIPA Type Gel Capsules}

A typical synthesis of AA-NIPA type gel capsules was as follows. A dozen of DAA-NIPA type gel capsules $\left(r_{\mathrm{t}} / R_{0}=0.90\right)$ were neutralized with acetic acid solution in methanol with Soxhlet extractor for 3 days. After the reaction, they were sufficiently washed with methanol with a Soxhlet extractor. They were dried carefully and slowly, and finally dried in vacuo at $60^{\circ} \mathrm{C}$ until constant weight.

\section{Chemical Release from the Gel Capsule}

The gel capsule was dipped into a solution $(0.1 \mathrm{mmol}$ $\mathrm{L}^{-1}$ ) of Methyl Orange in methanol-acetone mixture $(1: 1)$ and allowed to swell for 1 day at $30^{\circ} \mathrm{C}$. After drying, the shell layer was selectively washed with acetone by a Soxhlet extractor and dried again. The sample was placed in $50 \mathrm{~mL}$ water at $50^{\circ} \mathrm{C}$. $A_{\mathrm{t}}$, absorbance of the solution at $468.5 \mathrm{~nm}$ after $t$ min, was measured by a UV spectrophotometer.

\section{Measurement of Swelling Rate}

A sample was placed in water in a $50 \mathrm{~mL}$ cylindrical cell at a desired temperature. The change of external radius $\left(R^{\prime}{ }_{\mathrm{t}} / R^{\prime}{ }_{0}\right)$, where $2 R^{\prime}{ }_{0}$ and $2 R^{\prime}{ }_{\mathrm{t}}$ are external radii of the original gel and the gel swelled after $t=t \mathrm{~min}$, respectively, was recorded using the digital video camera system described above.

\section{Measurement of Equilibrium Swelling Ratio}

A sample was immersed in water at a desired temperature (the initial temperature was $50^{\circ} \mathrm{C}$ ). The equilibrium swelling ratio was measured according the method reported ${ }^{6 \mathrm{a}}$ It is defined as $\left(W_{\mathrm{s}}+W_{\mathrm{p}}\right) / W_{\mathrm{p}}$, where $W_{\mathrm{s}}$ and $W_{\mathrm{p}}$ are weights of absorbed water and dried polymer, respectively.

\section{RESULTS AND DISCUSSION}

\section{Synthesis of Poly(N-isopropylacrylamide) Gel by Ami-} dation of DAA gel

Amidation of a cylindrical DAA (length the same as diameter; about $5.0 \mathrm{~mm}$ ) with various concentrations of IPA solution was carried out in NMP using TPP at $80^{\circ} \mathrm{C}$. When DAA was placed in NMP containing excess amounts of IPA and TPP, the swelling occurred and the gel was divided into a swollen shell and unswollen cylindrical core (Figure 1). The shell expanded with decreasing the core in size during reaction. At the end of the reaction, the core disappeared. This reaction mode is similar to the esterification mode of DAA with alkyl halide. $^{2}$ The mechanism of the esterification was investigated in detail, ${ }^{2 c, d}$ and the heterogeneous reaction has three rates; intrinsic esterification rate of DBU salt of carboxylic acid with alkyl halide, diffusion rate of alkyl halide through a swollen part, and diffusion rate of alkyl halide through an unswollen part. It can be considered that only the part with high esterification swells in the solvent, and the degree of esterification is equal to any part in the shell layer when an excess amount of alkyl halide is added. The relative magnitude of intrinsic reaction rate for two diffusion rates caused the decreasing pattern of unswollen part to determine. Higashi et al. ${ }^{8 \mathrm{a}}$ reported that the amidation of $N$-benzoyloxycarbonylglycine with ethyl glycine hydrochloride using DPP-pyridine system as an activating reagent at room temperature for $30 \mathrm{~min}$ gave ethyl $\mathrm{N}$ benzoyloxycarbonylglycylglycinate in $92 \%$ yield. The amidation of DAA with IPA using TPP was faster than that using DPP (Table I). The decreasing pattern of unswollen part $\left[\left(1-r_{\mathrm{t}} / R_{0}\right) v s . t / \tau\right]$ was the same in all reaction, although the time $(\tau)$ for the complete disappearance of unswollen part depended on the reaction conditions (Figure 2). In addition, the decreasing pattern agreed with the esterification pattern of DAA with alkyl bromide. ${ }^{2 a, b}$ These results support similar reaction mechanism to diffusion control of the unreacted-core model $;{ }^{10}$ the intrinsic reaction is much faster than the diffusion rate of reagents through a swollen part using TPP, and the reaction zone is restricted to the boundary between the swollen part and the unswollen part. The amidation was carried out at various concentrations of TPP and IPA at $80^{\circ} \mathrm{C}$ in an aprotic polar solvent (Figure 3). The $\tau$ depended on the concentration of TPP, but was independent of the concentration of IPA. The $\tau$ became longer when the concentration of TPP was 


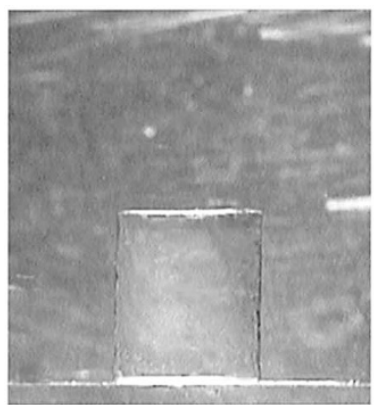

$\mathrm{Oh}$

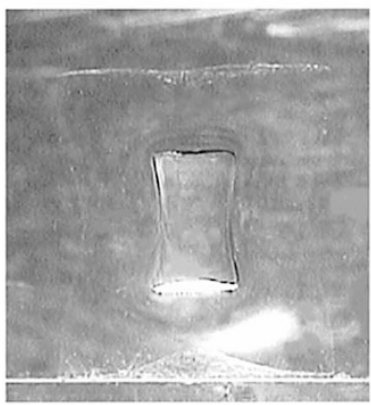

$6 \mathrm{~h}$

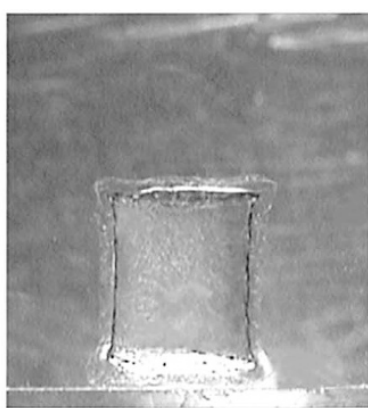

$1 \mathrm{~h}$

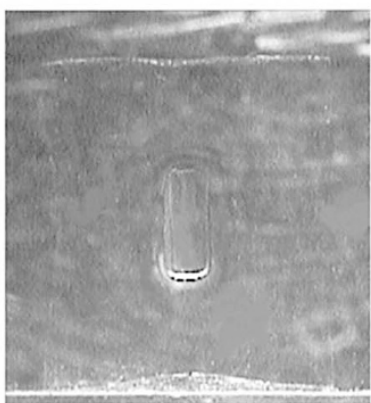

$12 \mathrm{~h}$

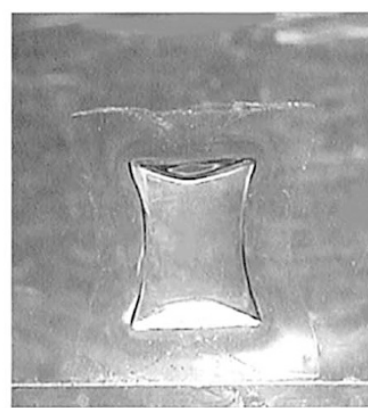

$3 \mathbf{h}$

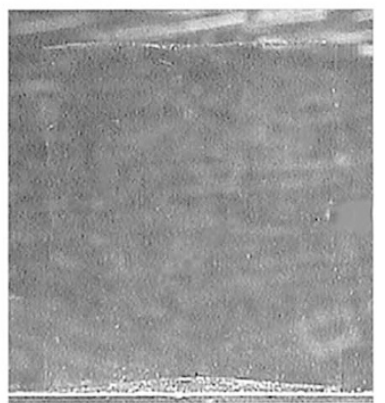

$16 \mathrm{~h}$

Figure 1. Typical photograsphs in reaction of DAA with a mixture solution of TPP $\left(1.0 \mathrm{~mol} \mathrm{~L}^{-1}\right)$ and IPA $(1.0 \mathrm{~mol} \mathrm{~L}-1)$ in NMP $(50 \mathrm{~mL})$ at $80^{\circ} \mathrm{C}$.

Table I. Reaction of DAA with IPA ${ }^{\mathrm{a}}$

\begin{tabular}{|c|c|c|c|c|c|}
\hline Gel & $\frac{\text { Conc. of IPA }}{\mathrm{mol} \mathrm{L}^{-1}}$ & $\frac{\text { Conc. of TPP }}{\mathrm{mol} \mathrm{L}^{-1}}$ & Solvent & $\frac{\tau}{\min }$ & $\frac{\mathrm{CI}^{\mathrm{b}}}{\mathrm{mol} \%}$ \\
\hline G-1 & 0 & 1.0 & NMP & 980 & $0^{\mathrm{d}}$ \\
\hline G-2 & 0.05 & 1.0 & NMP & 1010 & 32.0 \\
\hline G-3 & 0.3 & 1.0 & NMP & 980 & 84.1 \\
\hline G-4 & 1.0 & 1.0 & NMP & 970 & $96.2^{\mathrm{e}}$ \\
\hline G-5 & 1.0 & $1.0^{\mathrm{c}}$ & NMP & 2220 & - \\
\hline G-6 & 1.0 & 0.3 & NMP & 1880 & 95.8 \\
\hline G-7 & 1.0 & 0.5 & NMP & 1210 & - \\
\hline G-8 & 1.0 & 1.0 & $\mathrm{DMF}$ & 540 & 95.3 \\
\hline G-9 & 1.0 & 1.0 & DMSO & 700 & 91.9 \\
\hline G-10 & 1.0 & 1.0 & DMAc & 760 & 95.3 \\
\hline
\end{tabular}

${ }^{a}$ Reaction of DAA was carried out with a mixture solution of TPP $\left(1.0 \mathrm{~mol} \mathrm{~L}^{-1}\right)$ and IPA $\left(1.0 \mathrm{~mol} \mathrm{~L}^{-1}\right)$ in a solvent $(50 \mathrm{~mL})$ at $80^{\circ} \mathrm{C}$. ${ }^{\mathrm{b}} \mathrm{CI}$ : content of $N$-isopropylacrylamide unit, it was calculated by the IR spectrum as shown in eq $4 .{ }^{\mathrm{c}} \mathrm{DPP}$ was used instead of TPP. ${ }^{\mathrm{d}}$ Content of acrylic acid unit was $1.9 \mathrm{~mol} \%$ determined from the back-titration. ${ }^{\mathrm{e}}$ Acrylic acid unit was not detected by the back-titration.

adjusted to $10 \mathrm{~mol} \mathrm{~L}^{-1}$ (about 20 vol\%) or more, because TPP which is not a suitable solvent for this reaction increased too much in the reaction mixture. The rate increased nearly with decreasing molecular size of solvent in following order; DMF $>$ dimethylsulfoxide $($ DMSO) $>N, N$-dimethylacetamide $($ DMAc) $>$ NMP (Table I). This suggests that the overall reaction depends markedly on the diffusion rate of TPP and solvents through the reacted shell layer.

The complete reaction with various concentrations

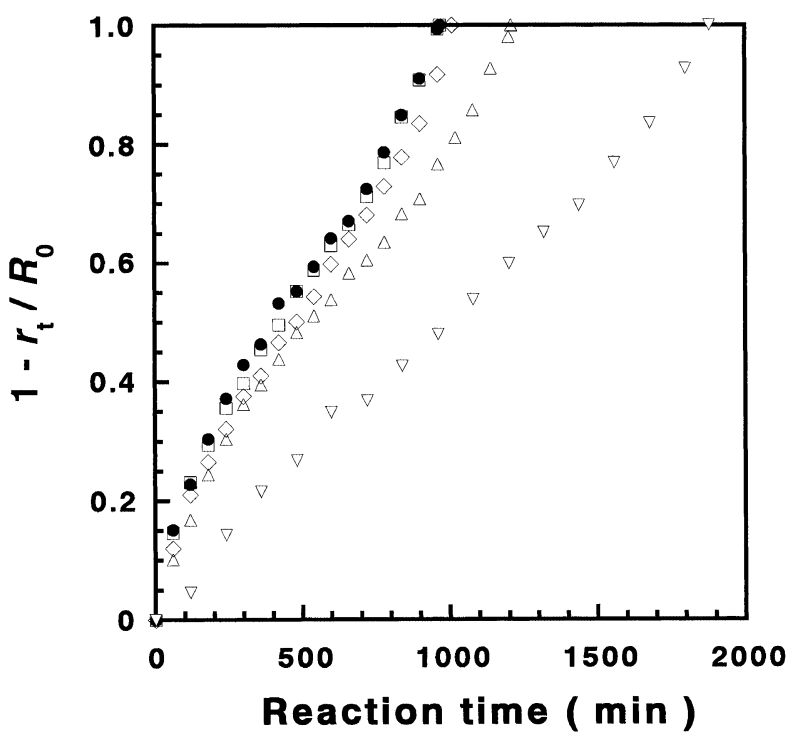

Figure 2. Amidation of DAA with concentrations of IPA in presence of TPP in NMP at $80^{\circ} \mathrm{C}$; $(\mathbf{O})[\mathrm{IPA}]_{0}=1.0 \mathrm{~mol} \mathrm{~L}^{-1}$, $[\mathrm{TPP}]_{0}=1.0 \mathrm{~mol} \mathrm{~L}-1,[\diamond][\mathrm{IPA}]_{0}=0.05 \mathrm{~mol} \mathrm{~L}^{-1},[\mathrm{TPP}]_{0}=$ $1.0 \mathrm{~mol} \mathrm{~L}^{-1} ;[\square][\mathrm{IPA}]_{0}=0 \mathrm{~mol} \mathrm{~L}^{-1},[\mathrm{TPP}]_{0}=1.0 \mathrm{~mol} \mathrm{~L}^{-1} ;[\triangle]$ $[\mathrm{IPA}]_{0}=0.5 \mathrm{~mol} \mathrm{~L}^{-1},[\mathrm{TPP}]_{0}=1.0 \mathrm{~mol} \mathrm{~L}^{-1} ;[\nabla][\mathrm{IPA}]_{0}=0.3 \mathrm{~mol}$ $\mathrm{L}^{-1},[\mathrm{TPP}]_{0}=1.0 \mathrm{~mol} \mathrm{~L}^{-1}$.

$\left(0,0.05,0.3\right.$, and $\left.1.0 \mathrm{~mol} \mathrm{~L}^{-1}\right)$ of IPA solution gave G-1-G-4 in the presence of TPP $\left(1.0 \mathrm{~mol} \mathrm{~L}^{-1}\right)$, respectively. G-4 was swollen in many solvents such as water, methanol, acetone, benzene, and NMP; however, G-1 was hardly swollen in protic solvents such as water and methanol. The IR spectra of these gels are shown in Figure 4. The spectrum of G- 


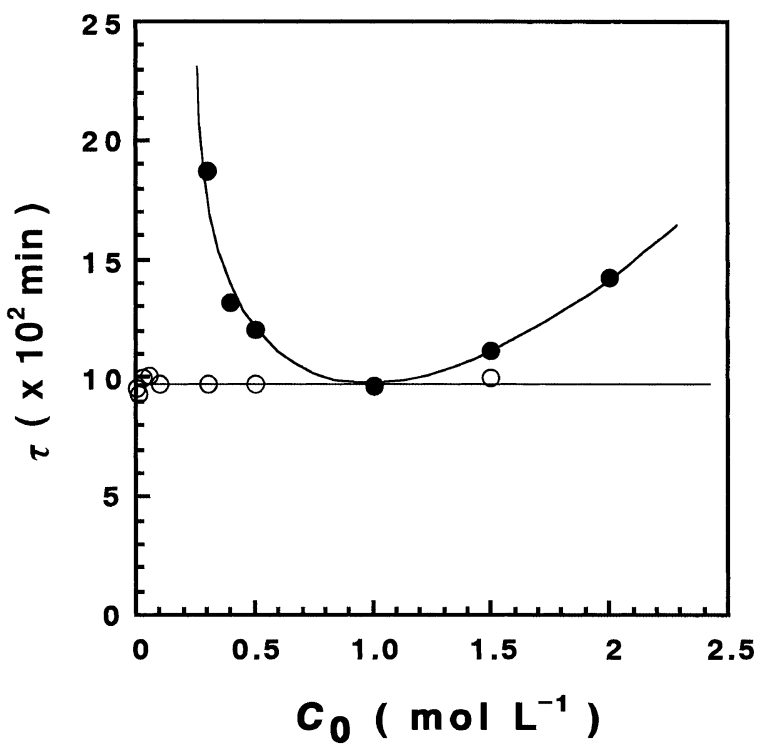

Figure 3. Dependence of time $(\tau)$ for the complete reaction on concentrations $\left(C_{0}\right)$ of IPA and TPP: $(\bigcirc)$ : $[\mathrm{TPP}]_{0}=1.0 \mathrm{~mol} \mathrm{~L}^{-1}$; (O): $[\mathrm{IPA}]_{0}=1.0 \mathrm{~mol} \mathrm{~L}^{-1}$.

4 showing strong absorptions at 1650, 1545 (amide I and amide II), and $3300 \mathrm{~cm}^{-1}(\mathrm{~N}-\mathrm{H}$, stretching) was different from that of $\mathrm{AA}$, and almost the same as that of $\operatorname{poly}(N$-isopropylacrylamide). The spectrum of G-1 showed strong absorption at $1755 \mathrm{~cm}^{-1}$ $(\mathrm{C}=\mathrm{O}$ of ester, stretching), and was consistent with that of poly(phenyl acrylate). The content of acrylic acid unit in G-1 was $1.9 \mathrm{~mol} \%$, calculated from the back-titration using the triethylamine solution in THF $\left(10 \mathrm{mmol} \mathrm{L}^{-1}\right)-10 \mathrm{mmol} \mathrm{L}^{-1}$ aqueous $\mathrm{HCl}$ solution according to the reported procedure. ${ }^{3 \mathrm{~b}}$ Therefore, the quantitative esterification of DAA with TPP occurred to yield the poly(phenyl acrylate) gel under these conditions. The spectrum of G-2 showed mixed absorptions based on poly ( $N$-isopropylacrylamide) and poly(phenyl acrylate). This spectral data indicated that G-2 is a copolymer of $N$-isopropylacrylamide and phenyl acrylate with $0.5 \mathrm{~mol} \%$ of $N, N^{\prime}$ methylenebisacrylamide. Since absorptions of mixture films of $\operatorname{poly}\left(N\right.$-isopropylacrylamide) at $1650 \mathrm{~cm}^{-1}$ ( $\left.A_{\text {amide }}\right)$ and poly(phenyl acrylate) at $1755 \mathrm{~cm}^{-1}\left(A_{\text {ester }}\right)$ were not overlapped, the $A_{\text {ester }} / A_{\text {amide }}$ was proportional to the wide molar ratio of phenyl acrylate unit $(y)$ to $N$-isopropylacrylamide unit $(x)$ in the mixtures (eq 4).

$$
y / x=1.31\left(A_{\text {ester }} / A_{\text {amide }}\right)
$$

From the relation, the contents of $\mathrm{N}$-isopropylacrylamide units in theamidated gel, which was regarded as a copolymer of phenyl acrylate and $\mathrm{N}$ isopropylacrylamide with $0.5 \mathrm{~mol} \%$ of $N, N^{\prime}$-methylenebisacrylamide, can be estimated. The calculated contents of $\mathrm{N}$-isopropylacrylamide units of G-2, G-3,

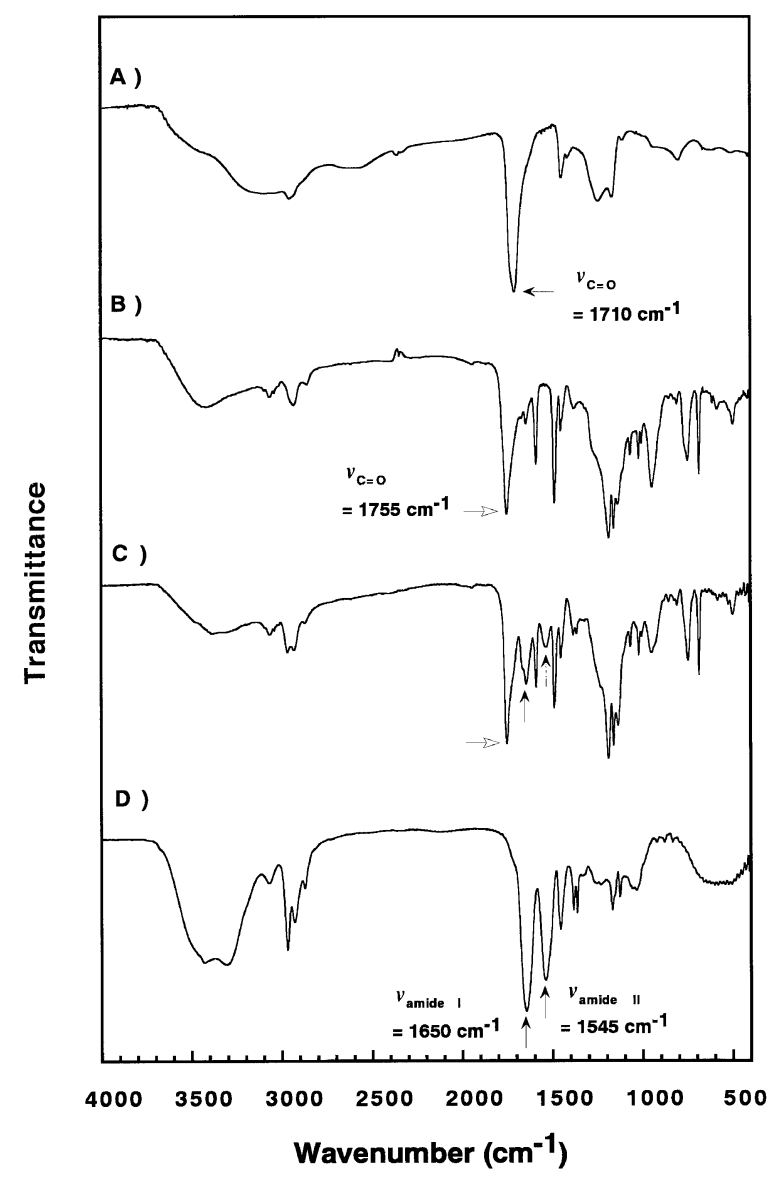

Figure 4. IR spectra (KBr) of A) AA gel, B) G-1, C) G-2, and D) G-4.

and G-4 were 32.0, 84.1, and $96.2 \mathrm{~mol} \%$, respectively. In addition, the content of acrylic acid units in G-4 was not detected by the back-titration described above. These results suggested that the amidation of DAA with IPA took place preferentially when high concentration $\left(1.0 \mathrm{~mol} \mathrm{~L}^{-1}\right)$ of IPA solution was used. Yamazaki and Higashi ${ }^{\text {a }}$ investigated the reaction of carboxylic acid with amine using pyridine-TPP or DPP system, and proposed the reaction mechanism through acyloxy $N$ phosphonium salt of pyridine. The reaction of carboxylic acid-DBU salt with IPA in the presence of TPP can be explained similarly to that using TPP-pyridine system as shown in Scheme 2. Since this reaction was independent of the concentration of IPA, it seems that the formation of intermediate was a rate-determining step, and the reaction of the intermediate with IPA or phenol was very fast. Therefore, the formation of intermediate is an important factor for smooth reaction, and may be attributed to balance between basicities of IPA and tertiary amine such as pyridine or DBU. A weaker tertiary amine such as pyridine than IPA was difficult to form the acyloxy $N$-phosphonium salt. However, IPA did not inhibit with the formation of intermediate of DBU because DBU $\left(p K_{\mathrm{a}}=11.5\right)$ is stronger base than IPA and pyridine $\left(p K_{\mathrm{a}}=5.25\right)$. The intermediate can 

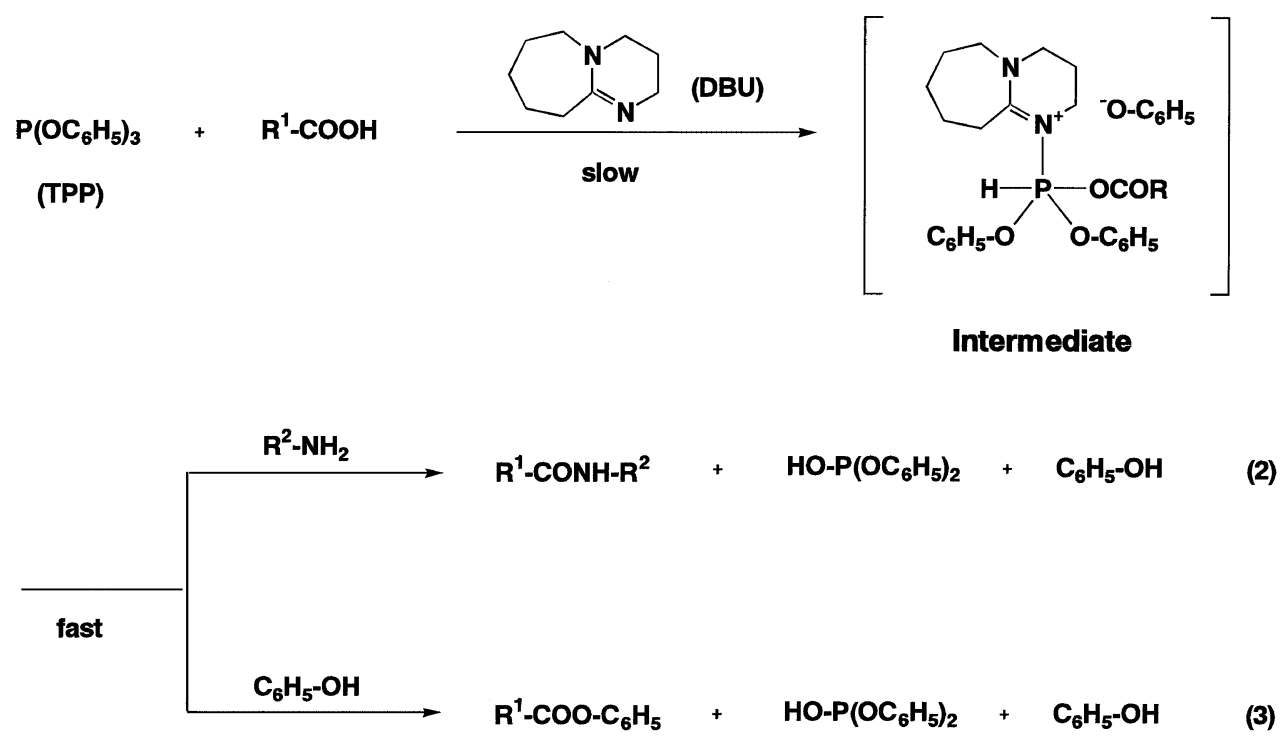

Scheme 2. Reaction mechanism of carboxylic acid with amine using TPP-DBU system.

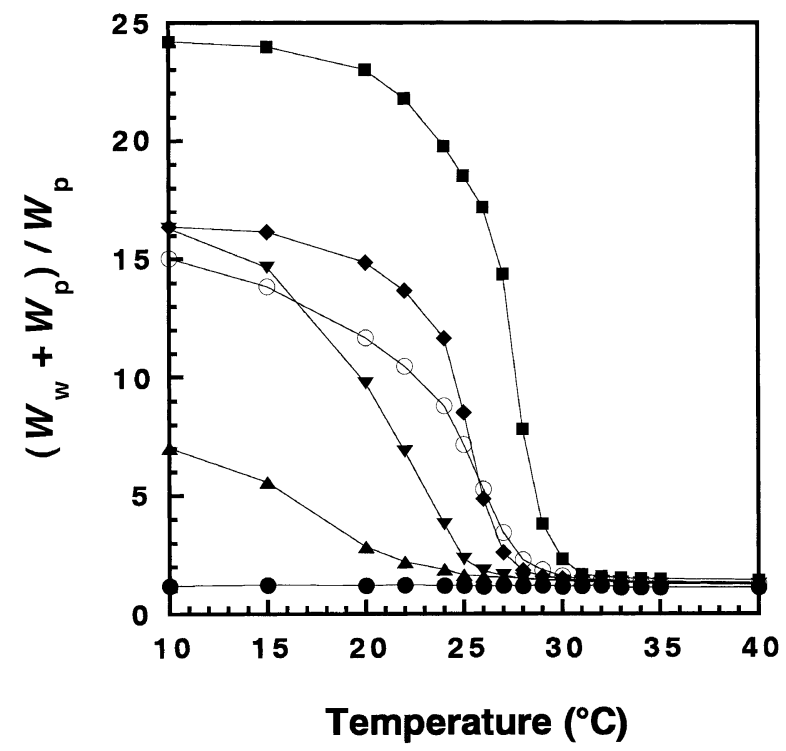

Figure 5. Equilibrium swelling ratio of gels obtained from the amidation in water as a function of temperature; $(\boldsymbol{O})$ : G-2; $(\boldsymbol{\Delta})$ : G-3; $(\mathbf{\square}):$ G-4; $(\boldsymbol{\nabla})$ G-8; $(\boldsymbol{\nabla}):$ G-9; $(\bigcirc):$ G-10.

react with IPA and phenol resulting as a by-product to give the corresponding amide and phenyl ester, respectively. Under homogeneous conditions, the aminolysis proceeds preferentially since IPA shows much higher nucleophilicity than phenol. As the intrinsic amidation rate was much faster than the diffusion rate of IPA and phenol through the swollen part in the reaction of gel, the concentration of the resulting phenol was high and the concentration of IPA was very low in the reaction zone. Under these diffusion control conditions of the unreacted core model, ${ }^{10}$ the esterification took place in competition with the amidation to give a copolymer of $\mathrm{N}$-isopropylacrylamide with phenyl acrylate.

The equilibrium swelling ratio of gels obtained from the reaction was measured in water at a wide range of temperature (Figure 5). The LCST of copolymer of $\mathrm{N}$-isopropylacrylamide is very sensitive to content and hydrophilicity of the comonomer unit. ${ }^{6}$ If the obtained gel contained small amounts of unreacted DBU salts or free carboxylic acids, the LCST was higher than $32^{\circ} \mathrm{C}$. For example, poly $(N$-isopropylacrylamide $)$ gel containing $1.0 \mathrm{~mol} \%$ of hydrophilic acrylic acid units showed LCST around $35^{\circ} \mathrm{C}$, and G-4 showed almost the same LCST at about $30^{\circ} \mathrm{C}$ as the corresponding gel (content of phenyl acrylate units: $4.8 \mathrm{~mol} \%$ ) obtained from copolymerization of $\mathrm{N}$-isopropylacrylamide with phenyl acrylate. ${ }^{9}$ These indicated that the reaction of DAA with excess amounts of IPA and TPP proceeded quantitatively to give poly( $N$-isopropylacrylamide) gel with small amounts of phenyl acrylate units as byproducts under these conditions. The content of phenyl acrylate units in the obtained gel was also dependent on the IPA concentration and the reaction solvent. The LCST and the equilibrium swelling ratio became lower with increasing the content of hydrophobic phenyl acrylate units. When NMP was used as a solvent, the obtained gel showed LCST at about $30^{\circ} \mathrm{C}$ close to that of poly( $N$-isopropylacrylamide) gel.

\section{Synthesis and Properties of a Gel Capsule}

A gel capsule (DAA-NIPA type gel capsule, $r_{\mathrm{t}} / R_{0}=$ 0.90 ) was synthesized from the amidation of DAA with IPA using TPP in NMP at $80^{\circ} \mathrm{C}$ for $55 \mathrm{~min}$. When the obtained gel capsule was dipped in water at $40^{\circ} \mathrm{C}$, the swelling took place as shown in Figure 6. The swelling was evaluated by $R^{\prime}{ }_{\mathrm{t}} / R^{\prime}{ }_{0}$, where $R_{0}^{\prime}$ and $R^{\prime}{ }_{\mathrm{t}}$ are external radii of the dried gel and the gel swelled in the solvent for $t$ min, respectively. Since thermosensitive poly( $N$-isopropylacrylamide) gel became hydrophobic and was hardly swollen in water at $40^{\circ} \mathrm{C}$ 


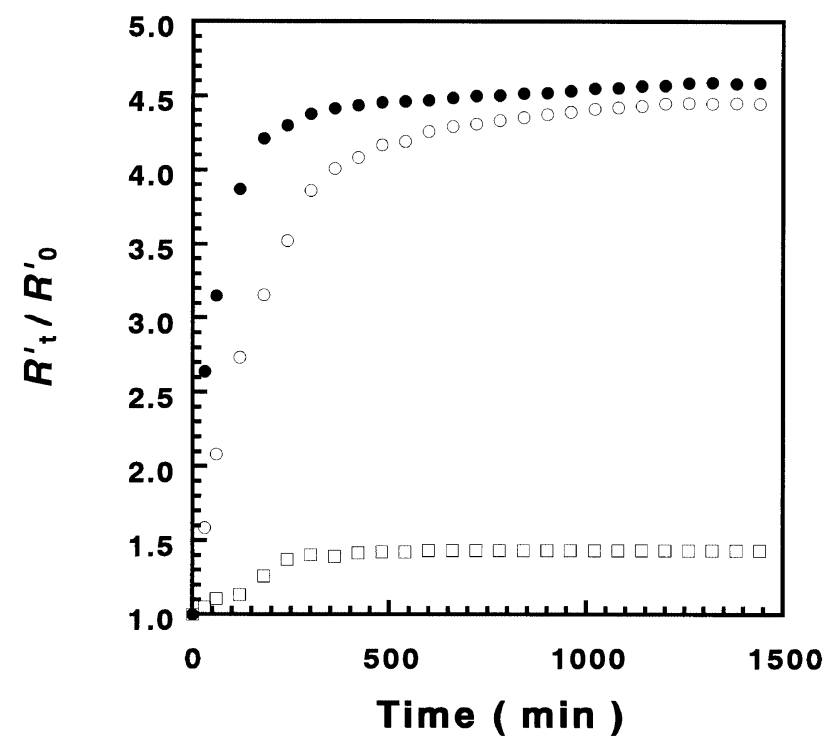

Figure 6. The swelling rate of gels in water at $45^{\circ} \mathrm{C}$ : DAA; ( $\square)$ : G-4; (O): DAA-NIPA type gel capsule.

$\mathbf{O h}$

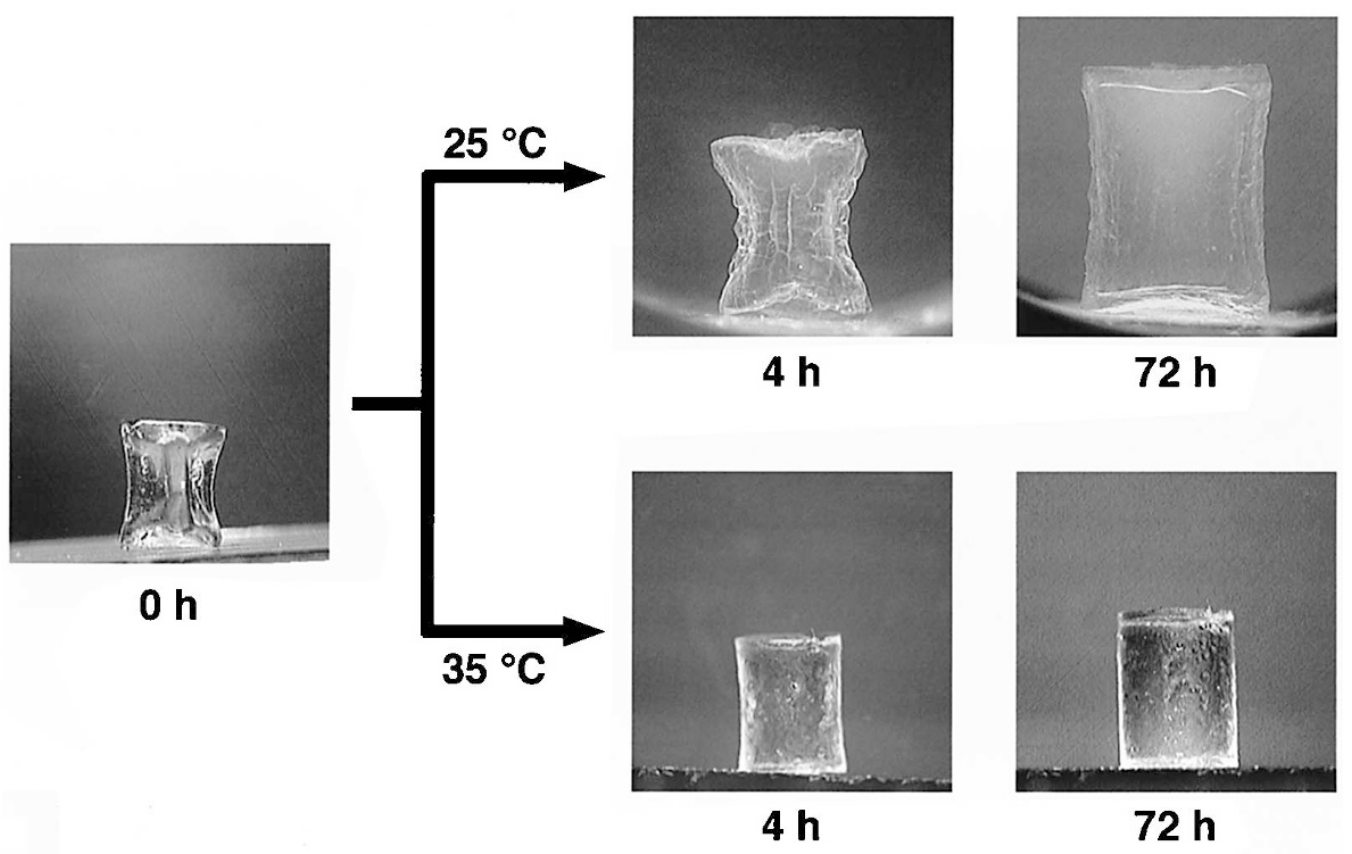

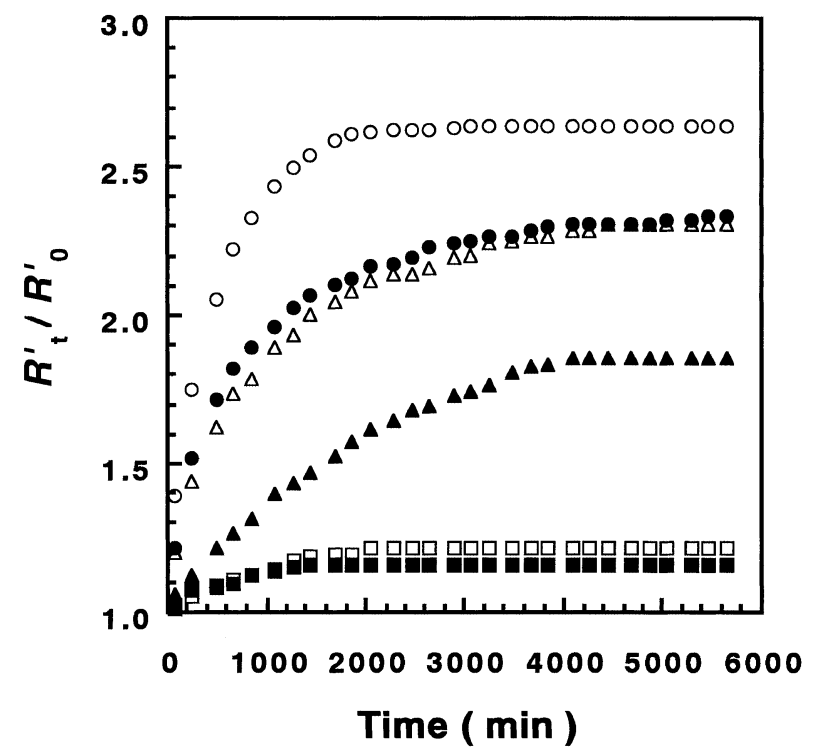

Figure 7. The swelling rate of AA-NIPA type gel capsule in water: $(\mathbf{O}): 20^{\circ} \mathrm{C} ;(\triangle): 25^{\circ} \mathrm{C} ;(\boldsymbol{\Delta}): 30^{\circ} \mathrm{C} ;(\square): 35^{\circ} \mathrm{C} ;(\mathbf{\square}): 40^{\circ} \mathrm{C}$; (○): AA gel at $30^{\circ} \mathrm{C}$.

Figure 8. Typical photographs in swelling of AA-NIPA type gel capsule in water.

which is higher temperature than the LCST, the shell layer was expected to depress the swelling of the core part. However, this effect of shell layer was not recognized at all, and the gel capsule showed almost the same swelling behavior as DAA. The fact that the transition of poly ( $N$-isopropylacrylamide) gel in the shell layer did not occur may be attributed to the strong waterabsorbing power of DAA in the core part. In order to improve this, the conversion of DAA in the core part to AA gel, which had much lower water-absorbing power than DAA, gave a novel AA-NIPA type gel capsule consisting of a hydrophilic AA core and thermo- sensitive poly( $N$-isopropylacrylamide) shell. The AANIPA type gel capsule was easily prepared from the neutralization of DAA-NIPA type gel capsule washed with methanol containing a small amount of acetic acid by a Soxhlet extractor. As the conversion of DAA (molecular weight of monomer unit: 224.3) to AA gel (molecular weight of monomer unit: 72.1) was accompanied with a big volume shrinkage, the resulting AANIPA type gel had some dimples on its surface. The swelling behavior of AA-NIPA type gel capsule was measured in water at various temperatures (Figure 7). When the water temperature $\left(20\right.$ or $\left.25^{\circ} \mathrm{C}\right)$ was lower 


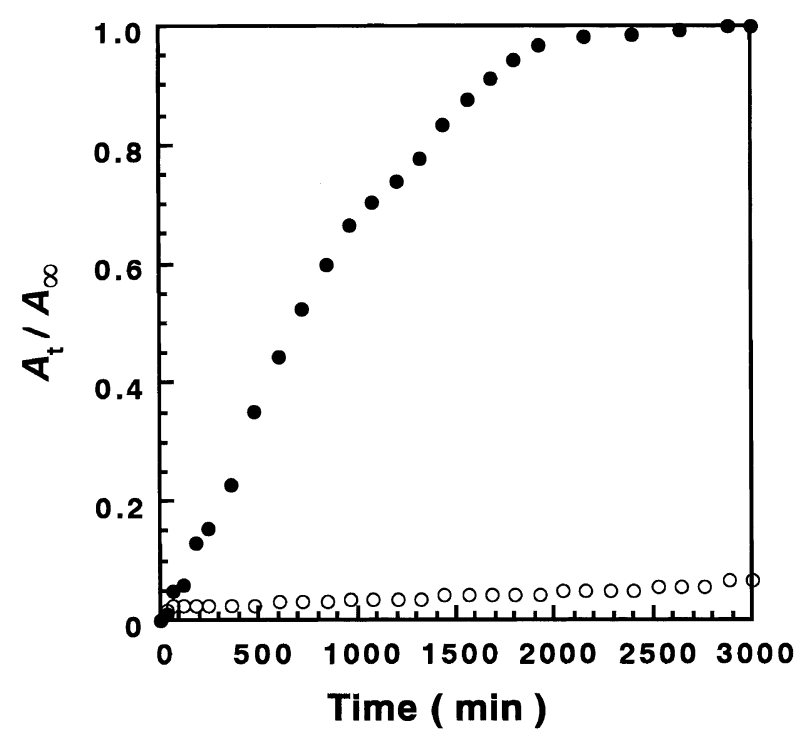

Figure 9. Methyl Orange release profiles from AA-NIPA type gel capsule: $(\bigcirc): 25^{\circ} \mathrm{C} ;(\bullet): 35^{\circ} \mathrm{C}$.

than the LCST, the shell layer as well as the core part swelled. When the temperature $\left(35\right.$ or $\left.40^{\circ} \mathrm{C}\right)$ was higher than the LCST, the gel capsule was slightly swelled since the shell layer became hydrophobic. Also, the pictures of gel capsules equilibrated in water at 25 and $35^{\circ} \mathrm{C}$ were shown in Figure 8. The difference between the two gel states; swelling state and no swelling state, was so large that the properties of shell layer were expected to change dramatically in response to the temperature changes. When the temperature was the vicinity of the LCST, the gel showed the transition between the two gel states. Therefore, the shell layer showed the LCST at about $30^{\circ} \mathrm{C}$ by exchanging DAA for AA gel in the core part, and worked as a permeability barrier of water at the high temperature. When an AA-NIPA type gel capsule with dye in the core part was put in water, the swelling of shell layer at $25^{\circ} \mathrm{C}$ caused dye in the core part to diffuse through the shell layer and to release outside (Figure 9). However, dye was hardly released since the shell layer was not swollen at $35^{\circ} \mathrm{C}$. Accordingly, at the low temperature, the chemical release became a state of "on" and became a state of "off" at the high temperature. Furthermore, the chemical release of dye from the gel capsule was observed in water when the temperature was changed stepwisely between $25^{\circ} \mathrm{C}$ and $35^{\circ} \mathrm{C}$ every $6 \mathrm{~h}$ (Figure 10 ). The swelling of gel capsule and the chemical release was not detected at $35^{\circ} \mathrm{C}$. When the temperature dropped to $25^{\circ} \mathrm{C}$ after $6 \mathrm{~h}$, the swelling of gel capsule and the release of dye started in response to the swelling of shell layer. As soon as the temperature was raised to $35^{\circ} \mathrm{C}$, the shell layer shrank again. The shrinking caused the swelling of gel capsule and the release of dye to stop. The same changes were repeated in response to the stepwise tem-

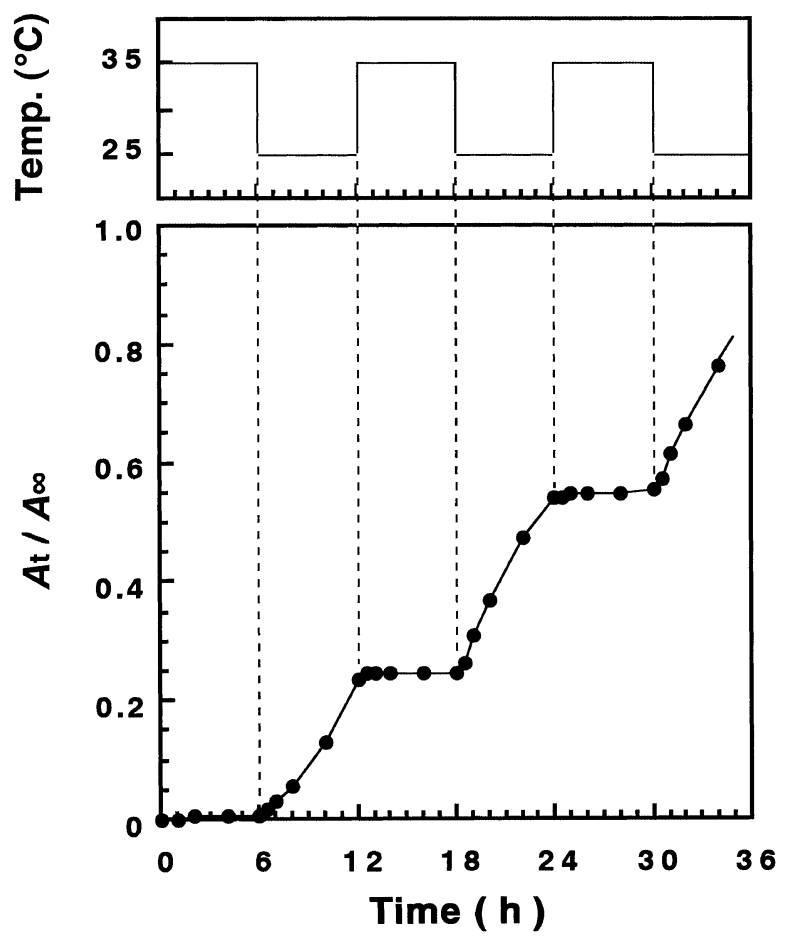

Figure 10. Methyl Orange release profiles from AA-NIPA type gel capsule in response to stepwise temperature change.

perature changes. The swelling and deswelling phenomenon of shell layer played a role as a switch for the drug release (Scheme 3). Similar phenomenon has been observed in chemical release from $\operatorname{poly}(N-$ isopropylacrylamide) gel. ${ }^{6 a}$ The deswelling of $\operatorname{poly}(N-$ isopropylacrylamide) gel swelled in water caused the gel to develop the dense surface skin layer which acted the same as the shell layer of gel capsule. The gel shrank very slowly with increase of the skin layer to original size and with slow release of water and chemicals. In contrast, the AA-NIPA type gel capsule swelled in water did not show the shrinkage when it was placed in water at $35^{\circ} \mathrm{C}$. Therefore, AA-NIPA type gel capsule is different from poly( $N$-isopropylacrylamide) gel in the swelling -deswelling characteristic for temperature. These results suggest that AA-NIPA type gel capsule is useful for novel thermo-sensitive drug carrier.

\section{CONCLUSION}

The synthesis of poly( $N$-isopropylacrylamide) gel and the gel capsule have been investigated by the amidation of DAA with IPA using TPP as an activating regent and the following conclusions have been obtained:

(1) The reaction DAA with IPA using TPP as an activating agent took place from the outside to give a core-shell type gel containing a reacted shell layer and unreacted core part. The decreasing pattern of unreacted core part agreed with the esterification pattern of DAA with alkyl bromide. The reaction 

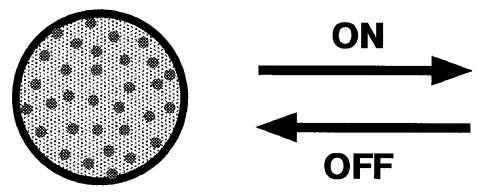

$T_{1}>$ LCST

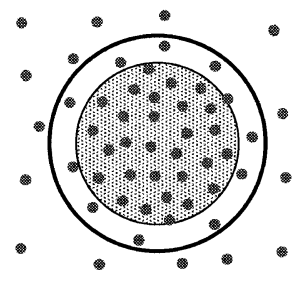

$T_{2}<$ LCST $\square$ : Swollen shell layer

: Dense shell layer (permeability barrier)

\section{: Core part}

- : Dye

Scheme 3. Schematic illustration of on-off chemical release in response to stepwise temperature changes $\left(T_{1}=35^{\circ} \mathrm{C}, T_{2}=25^{\circ} \mathrm{C}\right)$.

rate depended on the concentration of TPP, but was independent of the concentration of IPA.

(2) This reaction gave a wide variety of copolymer gels of $N$-isopropylacrylamide with phenyl acrylate. The selectivity of amidation was controlled by the reaction conditions such as the reaction solvent and the concentration of IPA. When the reaction with excess amounts of IPA was carried out at $80^{\circ} \mathrm{C}$ in NMP, a thermo-sensitive gel which showed almost the same properties as $\operatorname{poly}(N$ isopropylacrylamide) gel was obtained.

(3) The selective amidation from the outside afforded a DAA-NIPA type gel capsule consisting of a hydrophilic unreacted core and $\operatorname{poly}(N$ isopropylacrylamide) shell. However, the shell layer was also swollen and did not depress the swelling of the core part when the gel was place in water at a higher temperature than the LCST.

(4) The AA-NIPA type gel capsule was prepared from the neutralization of DAA-NIPA type gel capsule. The shell layer worked as a permeability barrier of chemicals in water at a higher temperature than the LCST. In addition, the gel capsule showed on-off chemical release in response to stepwise temperature changes cross the LCST of the shell layer.

\section{REFERENCES}

1. a) T. Shimokawa and T. Nishikubo, Kobunshi Ronbunshu, 44, 641 (1987).

b) T. Shimokawa and T. Nishikubo, Kobunshi Ronbunshu, 49, 577 (1992).

c) T. Nishikubo, T. Iizawa, A. Takahashi, and T. Shimokawa, J. Polym. Sci., Part A: Polym. Chem., 28, 105 (1990).

d) T. Iizawa, K. Nishiyama, and T. Nishikubo, J. Photopolym. Sci. Technol., 3, 125 (1990).

e) T. Iizawa, K. Nishiyama, and T. Nishikubo, J. Polym. Sci., Part A: Polym. Chem., 31, 443 (1993).

f) T. Iizawa and Y. Sato, Polymer J., 24, 991 (1992).

g) T. Iizawa and E. Seno, Polym. J., 24, 1169 (1992). h) T. Iizawa and T. Ogasa, J. Polym. Sci., Part A: Polym. Chem., 34, 63 (1996).

i) T. Nishikubo, A. Kameyama, Y. Yamada, and Y. Yoshida, J. Polym. Sci., Part A: Polym. Chem., 34, 3531 (1996).

j) A. Kameyama, M. Suzuki, K. Ozaki, and T. Nishikubo, Polym. J., 28, 155 (1996).

2. a) T. Iizawa and F. Matsuda, Polym. J., 30, 155 (1998).

b) F. Matsuda, S. Miyamoto, and T. Iizawa, Polym. J., 31, 435 (1999).

c) F. Matsuda, N. Matsuno, and T. Iizawa, Kobunshi Ronbunshu, 55, 439 (1998).

d) T. Iizawa, S. Miyamoto, and S. Sugano, Kobunshi Ronbunshu, 57, 715 (2000).

3. a) T. Iizawa, T. Fujimoto, and F. Matsuda, Polym. J., 29, 784 (1997).

b) T. Iizawa and T. Fujimoto, Kobunshi Ronbunshu, 55, 490 (1998).

c) F. Matsuda, T. Fujimoto, and T. Iizawa, Kobunshi Ronbunshu, 55, 697 (1998).

d) T. Iizawa, T. Fujimoto, E. Miyata, and F. Matsuda, Kobunshi Ronbunshu, 59, 21 (2002).

4. a) M. Heskins and J. E. Guillet, J. Macromol. Sci. Chem., A2, 1441 (1968).

b) S. Hirotsu, Y. Hirokawa, and T. Tanaka, J. Chem. Phys., 87, 1392 (1987).

c) S. Fujishige, K. Kubota, and I. Ando, J. Phys. Chem., 93, 3311 (1989).

5. M. Akashi, S. Nakano, and A. Kishida, J. Polym. Sci., Part A: Polym. Chem., 34, 301 (1996).

6. For example,

a) T. Okano, Y. H. Bae, H. Jacobs, and S. W. Kim, J. Controlled Release, 11, 255 (1990).

b) L. Dong and A. S. Hoffman, J. Controlled Release, 15, 141 (1991).

7. a) F. Higashi, J. Synth. Org. Chem. Jpn., 47, 995 (1989).

b) M. Ueda, J. Synth. Org. Chem. Jpn., 48, 144 (1990).

8. a) N. Yamazaki and F. Higashi, Tetrahedron Lett., 49, 5047 (1972).

b) N. Yamazaki and F. Higashi, Tetrahedron, 30, 1323 (1974).

9. T. Iizawa, N. Matsuno, M. Takeuchi, and F. Matsuda, Polym. J., 31, 1277 (1999).

10. a) S. Yagi and T. Kunii, Kogyo Kagaku Zasshi, 56, 131 (1953). b) O. Levenspiel, "Chemical Reaction Engineering”, John Wiley \& Sons, Inc., New York, N.Y., 1972, p 372. 